\title{
LESSONS LEARNED FROM THE APPLICATION OF ENHANCED FUNCTION-MEANS MODELLING
}

\author{
J. R. Müller ${ }^{凶}$, M. D. I. Siiskonen and J. Malmqvist \\ Chalmers University of Technology, Sweden \\ $\bowtie$ jakob.muller@chalmers.se
}

\begin{abstract}
Although well researched and praised in academic publications, function modelling (FM) does not have gained much traction in industrial application. To investigate into possible reasons for this, this publication researches literature of nine different projects where enhanced function-means modelling has been applied. The projects are analysed for their purpose of FM-use, applied benefits and discovered challenges of the FM approach. From this, the main challenges for FM application are the abstraction level of the modelling language as well as the lack of an interface to CAD modelling.
\end{abstract}

Keywords: functional modelling, engineering design, concurrent engineering (CE), design knowledge, conceptual design

\section{Introduction}

Function modelling (FM) has been adopted as a support method for product development, e.g. for facilitating systemic product analysis (Raja and Isaksson, 2015), fostering collaborative design (Eisenbart et al., 2015) or exploring the design space (Müller et al., 2019).

However, despite the recognition that FM gets in academic publications, it has not been widely adopted in industrial product development processes (Tomiyama et al., 2013). This leads to the question why such versatile methods and tools have not been adopted by the engineering industry?

Earlier studies have researched the direct industrial application of FM methods (Eckert et al., 2012) and summarized FM related research and methods (Tomiyama et al., 2013). This publication aims to more deeply investigate one specific FM method and its application in several product development projects.

Enhanced function-means (EF-M) modelling is among the more industrially tested FM frameworks, and has been developed and used for over 20 years (for an early version, see Malmqvist, 1997).

To the best of our knowledge no follow-up studies on the EF-M modelling method in various industrial applications can be found. Thus, this publication brings together conclusions from multiple research projects performed in industrial collaboration by the Systems Engineering Design (SED) research group at Chalmers University of Technology, each applying EF-M in a product development case. The aims of this study is to identify the key purposes, benefits and limitations of the EF-M modelling method, and thereby provide a basis for future research and improvements to make EF-M, and FM in general, more applicable for product development.

The following research questions have been formulated to guide the research activities:

RQ1: What are the reasons for applying EF-M in product development projects? 
The research question aims at discovering in which design contexts the utilization of EF-M modelling as a product development method has proven useful.

RQ2: What are the limitations of EF-M as a means for product development support?

The scope of the limitations is based on the challenges that appeared when applying EF-M in the different projects that have been studied for this publication. These challenges have been collected and characterized.

The remainder of the paper is organized as follows: Section 2 explains the development of EF-M and the modelling framework. Section 3 describes the method of data collection and evaluation while section 4 presents findings such as the benefits of the EF-M modelling approach. Further, section 4 presents the research projects applying the EF-M modelling approach and finally, the identified challenges are described. In section 5, the findings of section 4 are discussed in relation to other FM methods. Lastly, section 6 concludes this study and suggests further research.

\section{Enhanced function-means modelling}

Function-means (F-M) modelling, the foundation of EF-M, describes a product as an alternating structure of functional requirements (FR) and respective means, called design solutions (DS). This is based on Hubka's law about the "hierarchy of subordinate functions, [...] determined by the chosen means" (Hubka and Eder, 1988), and creates a tree structure where each identified solution sprouts new functional requirements. Extending the F-M structure with constraints (C), a representation of limitations the solution needs to conform to and thus, directly motivate the design of a solution (Malmqvist, 1997) laid the basis for EF-M modelling. Schachinger and Johannesson (2000) enhanced this modelling approach with the addition of interactions (iw) between DS, enabling an EF-M model capable of representing the complexity of integrated product designs.

Furthermore, Schachinger and Johannesson (2000) extended the modelling approach to represent a bandwidth of alternative designs, in the form of several alternative DS to one FR. Therefore, alternative product concepts can be captured in one model, and can be instantiated into individual variants. To enable an analysis of the performance (represented through the FRs) and conformity to limitations (in the form of Cs) of the product represented in an EF-M model, the model can be coupled to different product behaviour representing models and documents (Johannesson and Claesson, 2005), and provide an interface to the representations of the product's physical parts through configurable components (CC).

The main modelling elements and their connections are illustrated in Figure 1. The lowest level of the resulting tree structure, the leaf or the "concrete" level, describes the product on the lowest level of abstraction, very close to the product's geometry. Opposed to that, the other identified DSs represent generic means, not physical objects (Gedell and Johannesson, 2012).

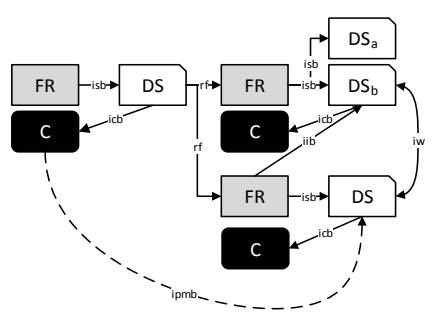

a

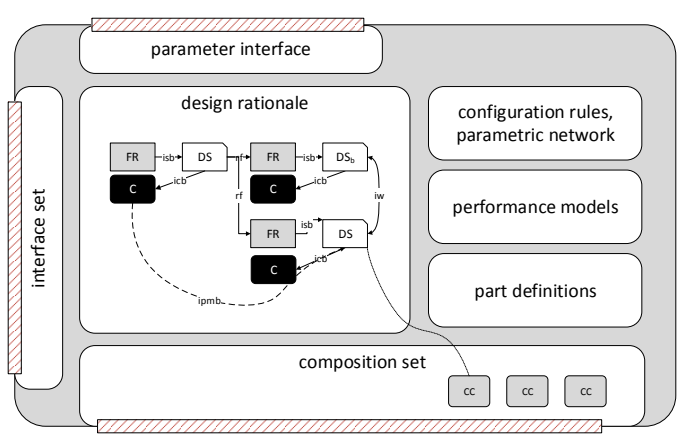

b

Figure 1. Modelling elements of a) EF-M and b) a Configurable Component, redrawn from Johannesson and Claesson (2005)

Figure 2 presents a practical example of an EF-M model. The presented EF-M model is based on the glue gun benchmark case, generated through functional decomposition workshop with participating researchers and adapted here in scale to fit this publication. 


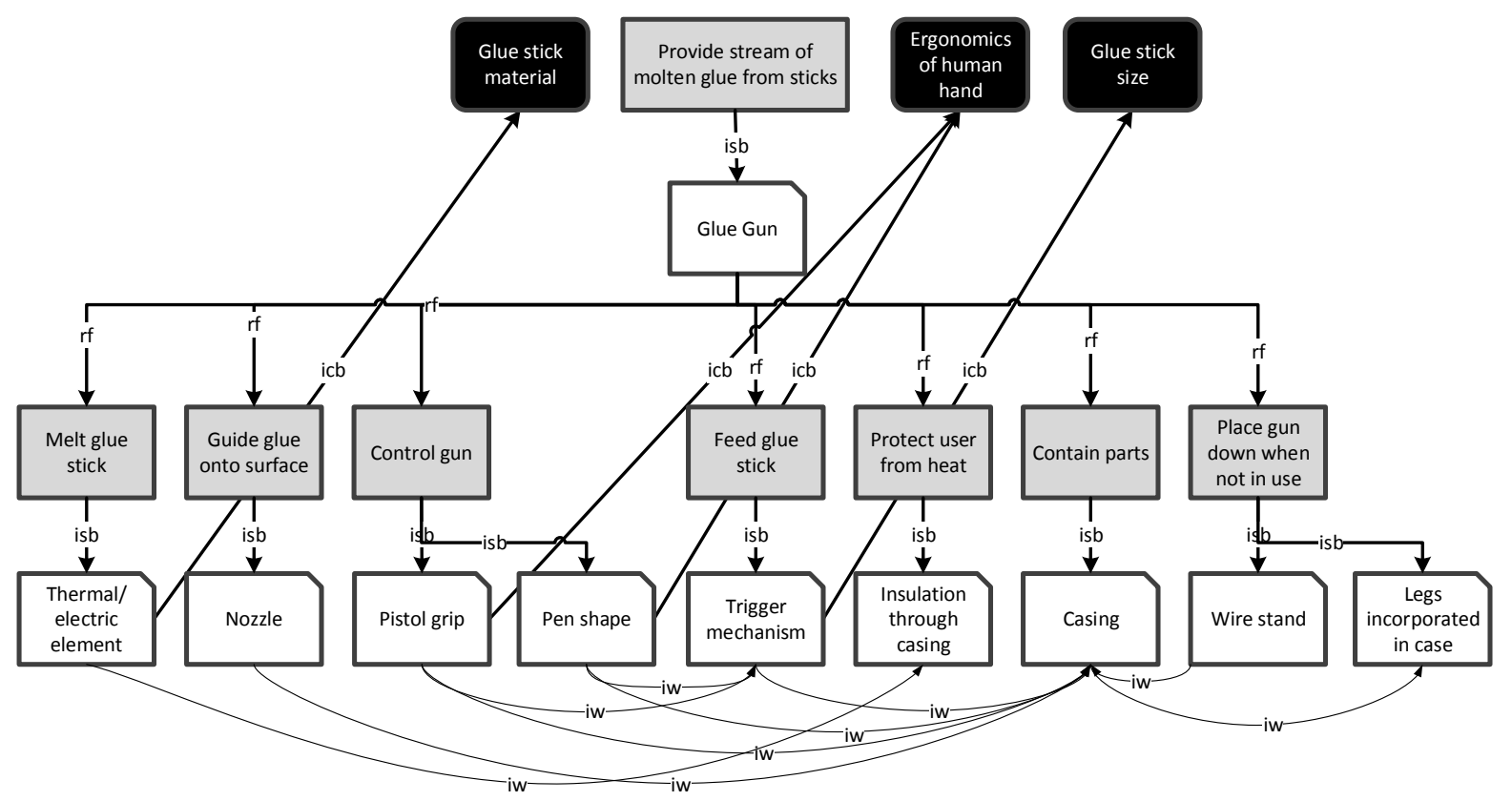

Figure 2. EF-M model of a glue gun

The glue gun has seven main functions. For two functions, alternative solutions are presented: different shapes to control the direction of the gun, and different ways to place the gun on the table when not in use.

The model shown in Figure demonstrates the ability to capture alternative DS for one FR, e.g. different handle shapes for the FR "Control gun". Furthermore, the use of constraints on different solutions is illustrated, i.e. the size of the glue stick which inflicts geometrical constraints onto the DS "Trigger mechanism". The iw between different DS can be seen at the bottom of the graph, capturing the interactions of the various DS with each other.

\section{Research approach}

This work is a retrospective study of research carried out in the SED research group at Chalmers University of Technology. Data collection was performed through a literature search about EF-M use cases, enabling a focus on the application of this one method and to not get distracted by the differences between different FM methods.

General literature about FM was used to generate an initial baseline of FM benefits and challenges, which were subsequently applied in the analysis of EF-M cases. These criteria were iteratively refined through the study of EF-M related literature and augmented to fit this specific modelling method.

From the body of publications about the application and development of EF-M, distinct projects were identified, most of them discussed in multiple publications. However, only one publication per project is used in this study as main reference. The inclusion criteria of the projects were as follows:

- EF-M should be used for product and/or production system design

- The application case should be an actual, "real", product

- The project should be carried out in collaboration with an industrial partner

Each project was categorized by its use of EF-M. The purpose and benefits of the method were identified by studying the product development task that was addressed by the means of EF-M. Furthermore, challenges in the application of EF-M in this project were collected from the publications and categorised, based on the initial set of challenges and benefits from general FM literature. Further, many projects complemented EF-M with additional models or methods to address the shortcomings of the EF-M method. The roles of these additional models and methods in each project were studied to shine light on possible shortcomings as well as opportunities for further development of the EF-M method. 


\section{Results}

From the literature research, nine different projects were deemed relevant. Table 1 summarizes these projects. For each project, the key reference, the context of the case, i.e. the industry of interest and the studied product and/or production system is presented.

Table 1. Use cases of EF-M in different studies, table headers $P$ for Purpose, $B$ for Benefits and $C$ for Challenges. Explanation of abbreviations see Table 2, 3 and 4

\begin{tabular}{|c|c|c|c|c|c|c|c|c|}
\hline$\#$ & Key reference & $\begin{array}{c}\text { Industrial } \\
\text { context }\end{array}$ & $\begin{array}{c}\text { Case } \\
\text { product }\end{array}$ & $\begin{array}{c}\text { Production } \\
\text { method }\end{array}$ & $\mathbf{P}$ & B & $\mathbf{C}$ & $\begin{array}{c}\text { Additional } \\
\text { methods used }\end{array}$ \\
\hline P1 & $\begin{array}{l}\text { Johannesson } \\
\text { and Claesson, } \\
2005\end{array}$ & $\begin{array}{l}\text { Automotive, } \\
\text { mechanical } \\
\text { design }\end{array}$ & $\begin{array}{l}\text { End } \\
\text { bracket } \\
\text { in a } \\
\text { cross-car } \\
\text { beam }\end{array}$ & - & $S$ & $\begin{array}{l}\mathrm{B} 2, \mathrm{~B} 4, \\
\mathrm{~B} 5, \mathrm{~B} 6\end{array}$ & $\mathrm{C} 4$ & - \\
\hline $\mathbf{P 2}$ & $\begin{array}{l}\text { Gedell and } \\
\text { Johannesson, } \\
2012\end{array}$ & $\begin{array}{l}\text { Automotive, } \\
\text { mechanical } \\
\text { design }\end{array}$ & $\begin{array}{l}\text { Car seat } \\
\text { case }\end{array}$ & - & $\mathrm{C}$ & $\begin{array}{l}\text { B4, B5, } \\
\text { B6 }\end{array}$ & $\mathrm{C} 1, \mathrm{C} 4$ & $\begin{array}{l}\text { Constraint } \\
\text { allocation } \\
\text { method }\end{array}$ \\
\hline P3 & $\begin{array}{l}\text { Levandowski } \\
\text { et al., } 2014\end{array}$ & $\begin{array}{l}\text { Aerospace, } \\
\text { mechanical } \\
\text { design }\end{array}$ & $\begin{array}{l}\text { Turbine } \\
\text { exhaust } \\
\text { case }\end{array}$ & Fabrication & $S$ & $\begin{array}{l}\text { B2, B3, } \\
\text { B6, B7 }\end{array}$ & $\begin{array}{l}\mathrm{C} 1, \mathrm{C} 2, \\
\mathrm{C} 3 \mathrm{C} 4\end{array}$ & CAD \\
\hline P4 & $\begin{array}{l}\text { Michaelis et } \\
\text { al., } 2015\end{array}$ & $\begin{array}{l}\text { Automotive, } \\
\text { mechanical } \\
\text { design }\end{array}$ & $\begin{array}{l}\text { Rear } \\
\text { header } \\
\text { roof } \\
\text { panel } \\
\text { case }\end{array}$ & Assembly & $\mathrm{C}$ & $\begin{array}{l}\text { B3, B4, } \\
\text { B6 }\end{array}$ & $\mathrm{C} 3, \mathrm{C} 4$ & $\begin{array}{l}\text { Component } \\
\text { trees }\end{array}$ \\
\hline P5 & $\begin{array}{l}\text { Raudberget et } \\
\text { al., } 2015\end{array}$ & $\begin{array}{l}\text { Aerospace, } \\
\text { mechanical } \\
\text { design }\end{array}$ & $\begin{array}{l}\text { Turbine } \\
\text { exhaust } \\
\text { case }\end{array}$ & - & $S$ & $\begin{array}{l}\text { B1, B3, } \\
\text { B4 }\end{array}$ & $\mathrm{C} 2$ & $\begin{array}{l}\text { CAD, DSM, } \\
\text { Change } \\
\text { Propagation }\end{array}$ \\
\hline P6 & $\begin{array}{l}\text { Landahl et al., } \\
2017\end{array}$ & $\begin{array}{l}\text { Aerospace, } \\
\text { mechanical } \\
\text { design }\end{array}$ & $\begin{array}{l}\text { Turbine } \\
\text { exhaust } \\
\text { case }\end{array}$ & Fabrication & $\mathrm{C}$ & $\begin{array}{l}\text { B1, B2, } \\
\text { B5 }\end{array}$ & $\mathrm{C} 2, \mathrm{C} 4$ & $\begin{array}{l}\text { CAD, CAE, } \\
\text { IPS, } \\
\text { Producibility } \\
\text { model }\end{array}$ \\
\hline P7 & $\begin{array}{l}\text { Borgue et al., } \\
2018\end{array}$ & $\begin{array}{l}\text { Aerospace, } \\
\text { mechanical } \\
\text { design }\end{array}$ & $\begin{array}{l}\text { Satellite } \\
\text { comp's } \\
\text { mechanic } \\
\text { al design }\end{array}$ & $\begin{array}{l}\text { Additive } \\
\text { manufact- } \\
\text { uring }\end{array}$ & $\mathrm{D}$ & $\begin{array}{l}\text { B1, B4, } \\
\text { B6, B7 }\end{array}$ & $\mathrm{C} 2, \mathrm{C} 4$ & $\mathrm{CAD}, \mathrm{CAE}$ \\
\hline P8 & $\begin{array}{l}\text { Müller et al., } \\
2019\end{array}$ & $\begin{array}{l}\text { Aerospace, } \\
\text { mechanical } \\
\text { design }\end{array}$ & $\begin{array}{l}\text { Turbine } \\
\text { rear } \\
\text { assembly }\end{array}$ & - & $\mathrm{D}$ & $\begin{array}{l}\text { B1, B3, } \\
\text { B4, B5, } \\
\text { B6, B7 }\end{array}$ & $\begin{array}{l}\mathrm{C} 1, \mathrm{C} 2, \\
\mathrm{C} 3, \mathrm{C} 4\end{array}$ & $\begin{array}{l}\text { CAD, CAE, } \\
\text { DSM }\end{array}$ \\
\hline P9 & $\begin{array}{l}\text { Siiskonen et } \\
\text { al., } 2018\end{array}$ & $\begin{array}{l}\text { Pharma- } \\
\text { ceutical, } \\
\text { mechanical } \\
\text { design }\end{array}$ & $\begin{array}{l}\text { Solid } \\
\text { oral } \\
\text { dosage } \\
\text { form }\end{array}$ & - & $\mathrm{M}$ & $\begin{array}{l}\text { B1, B2, } \\
\text { B4, B5, } \\
\text { B7, }\end{array}$ & $\begin{array}{l}\mathrm{C} 2, \mathrm{C} 3, \\
\mathrm{C} 4\end{array}$ & $\begin{array}{l}\text { Complexity } \\
\text { factor, SKU }\end{array}$ \\
\hline
\end{tabular}

\subsection{Benefits and purposes of the use of EF-M modelling}

One of the features of many FM methods is the ability to capture the DR (B4) and the justifications of the chosen functions and means of a product. Furthermore, EF-M is capable of presenting product knowledge which is not present in other product models, such as architectural decisions or dependencies between solutions.

Beyond this, many uses of EF-M are in the platform modelling context - representing a multitude of alternative designs. This is mainly possible due to the ability of representing the product architecture in the form of a modular bandwidth (P3, B2), thereby enabling the use of EF-M for mass customization (M), as shown by in e.g. P9. Beyond the modular bandwidth, the parameterisation of 
DS allows for a parametric bandwidth (P2, B5). Modularisation also enables the development of multiple concepts in parallel, i.e. adopting a set-based design (S) approach in P3. However, set-based design would not be possible without the ability to maintain an open design space throughout the modelling process (B1), as well as the ability to constrain the design space and to impose these constraints onto the available designs (B7).

Table 2. Benefits of EF-M derived from function modelling benefits in general

\begin{tabular}{|c|c|c|}
\hline & EF-M Benefits & Derived from: \\
\hline B1 & Holds an open design space & Set-based engineering (Sobek et al., 1999) \\
\hline B2 & Supports modularization & $\begin{array}{l}\text { Break down into sub-problems (Pahl et al., 2003; Suh, } \\
\text { 1990) }\end{array}$ \\
\hline B3 & $\begin{array}{l}\text { Enables systemic product } \\
\text { behaviour/property analysis }\end{array}$ & $\begin{array}{l}\text { Explain behaviour, working principles (Tomiyama et al., } \\
\text { 2013) }\end{array}$ \\
\hline B4 & Captures and stores design rationale & Presentation of purpose (Tomiyama et al., 2013) \\
\hline B5 & Provides a parametric bandwidth & $\begin{array}{l}\text { Set-based engineering (Sobek et al., 1999), exploration of } \\
\text { alternatives (Kang et al., 2011) }\end{array}$ \\
\hline B6 & $\begin{array}{l}\text { Supports simultaneous Top-Down and } \\
\text { Bottom-Up modelling }\end{array}$ & $\begin{array}{l}\text { Different levels of abstraction in functional decomposition } \\
\text { (Eckert et al., 2012) }\end{array}$ \\
\hline B7 & $\begin{array}{l}\text { Filters design alternatives through } \\
\text { constraint employment }\end{array}$ & Generation of valid concepts only (Kang et al., 2011) \\
\hline B8 & Captures variable design information & $\begin{array}{l}\text { Interorganizational communication purposes (Tomiyama et } \\
\text { al., 2013) }\end{array}$ \\
\hline
\end{tabular}

An explicit benefit of the modular bandwidth ability of the $\mathrm{CC}$ method is a variable product information exposure towards stakeholders in the supply chain, facilitating the choice of sharing relevant component information through specific CCs of the product (P1, P3) (B8). Thus, facilitating information sharing in-house and cross-companies and hence, supporting concurrent engineering $(\mathbf{C})$. Especially for the use of design space exploration (D), the ability to provide a bandwidth in both modules as well as parameters has shown beneficial. Design space exploration is not only dependant on the representation of alternative models, but also their selection (Kang et al., 2011). Therefore, the benefit of analysing the different concepts in a pre-geometric modelling phase has been shown valuable (P8, B3). The benefit of EF-M models to be generated in both a top-down (P4) as well as bottom-up (P7) contributes to the ability of exploring design spaces (B6).

Table 3. Purposes for which EF-M was applied in the investigated projects

\begin{tabular}{|l|l|}
\hline & Purpose \\
\hline M & Mass customization \\
\hline C & Concurrent engineering \\
\hline S & Set-based design \\
\hline D & Design space exploration \\
\hline
\end{tabular}

\subsubsection{Mass Customization (M)}

In P9, the ability of EF-M formalism to work with alternative DSs (B1) and defined DSs to satisfy varying bandwidths of FRs was used to support the customization of pharmaceutical products. This approach results in extended scopes of functional models for products to incorporate the ability to generate additional product variants, and hence, a means of supporting mass customization. $\mathbf{P 9}$ is further an example of utilizing the function-means formalism to support modularization strategies (B2). The resulting function-means model of a range of products, a systematic structure expressing each variant DR (B4) was used to conveniently cluster the functions into realizable components with the intent of resulting in a network of independently functioning subsystems or modules, that together constitute the whole product. The modularization utility aimed at enabling variety in products (B5), filtered to feasible solutions through the application of constraints (B7). 


\subsubsection{Concurrent engineering (C)}

An explicit example of coupling the product and manufacturing system is provided in $\mathbf{P 4}$. In this project, the interaction modelling ability of EF-M to integrated product and production system design was used, where the interactive behaviour of the separate entities was captured, thus, facilitating a concurrent engineering project. P4 also utilized the ability of expressing and then displaying the DR to support the case company in understanding the design intent of the product (B4), furthermore demonstrated the use of EF-M for both top-down as well as bottom-up modelling (B6). A similar, even further interdisciplinary connection between an EF-M model of the product and one of the production system is shown in P6, making use of the configuration ability (B5) of EF-M in both models, and the modularity of the product (B2) for the fabrication manufacturing concept.

Another interesting support for concurrent engineering was demonstrated in P2. The ability of the CC method to expose the desired design information to specific recipients, by allowing the sharing of explicit CC objects and the corresponding information of these and thus, facilitating information cross disciplines, in-house and beyond the organization (B8).

\subsubsection{Set-based design (S)}

The ability of EF-M formalism to express DR simultaneously captures product configuration information. The product configuration (B5) advantage was employed in P3, to create sets of design concepts. Additionally, the rules of configuration are further supported by incorporating constraints as configuration rules (B7). Additionally, the ability of EF-M to work with alternative DSs and defined DSs to satisfy varying bandwidths of FR was employed to create the sets of alternative designs - thereby elevating the variety of products above only variants into products with different functionality $(\mathbf{B} 2, \mathbf{B 5})$.

The ability to filter alternative designs based on constraints (B3) was used to maintain the amount of different designs, while still keeping the design space open (B1).

In P5, a similar approach was followed, efficiently establishing sets of architectural options (B2, B5) for product design, generating a platform of products which then could be analysed for their systemic product properties stored in the EF-M model (B3). However, where P1 extended the EF-M method through the introduction of the CC framework, introducing easier configurability (B5) and modularisation (B2), $\mathbf{P 5}$ relied on methods outside of EF-M to enable proper analysis of the product's behaviour. Through the evaluation of the interactions modelled in EF-M in a design structure matrix (DSM), coupled to a change propagation method, different architectural options can be compared against each other. Further, P5 utilized this ability for inventory purposes between design solutions, to make grounded decisions in inferior solution elimination, hence, illustrating the ability of fully complying to the principles of set-based design.

\subsubsection{Design space exploration (D)}

The explicit use of EF-M for design space exploration has only occurred in the later projects and can be seen as a development out of the set-based design approaches from earlier works. These projects (P7, P8) explicitly name the purpose of defining, populating and analysing the design space, which differs them from the earlier approaches aiming for a platform design (P3). Therefore, it is no surprise that they make use of the benefits of an open design space (B1) and constraint modelling (B7) to describe the design space. P7 uses constraints as a clear way to capture the limits to the available design space and filter for feasible solutions based on that. However, $\mathbf{P 8}$ falls back to reducing the number of possible concepts after their instantiation by filtering towards constraint fulfilment.

P8 demonstrates the ability of combining the bottom-up with top-down approach (B6), by first performing a functional decomposition of the satellite component and then re-designing for a sub-set of FR (B1). The bottom-up approach i.e. analysing the existing product design (architecture) and the justification of each design solution, was employed for an increased understanding of the design and simultaneously identify where redesign shall occur (B4).

In aiming to provide a basis for further product development stages, P7 used the EF-M model as a basis for computer aided-design (CAD) models, providing parameters and configuration rules (B5). These CAD models where then used for subsequent computer aided engineering (CAE) methods. The 
selection of concepts for these further steps was based on systemic product property analysis of information in the EF-M model (B3).

\subsection{Challenges}

The expressed key challenges of applying function-means modelling for product and (or) production system design are presented in Table 4.

Table 4. Challenges EF-M, as identified in EF-M projects

\begin{tabular}{|l|l|l|}
\hline & Challenges & Appeared in projects \\
\hline C1 & Too abstract, unclear modelling rules & P2-P3, P8 \\
\hline C2 & Lack of behaviour modelling & P3, P5-P9 \\
\hline C3 & Lacking coupling to manufacturing process representation & P3-P3, P8-P9 \\
\hline C4 & Need for geometrical embodiment & P1-P4, P6-P9 \\
\hline
\end{tabular}

\subsubsection{Too abstract, unclear modelling rules (C1)}

Unclear modelling rules in terms of constraint handling was already addressed in $\mathbf{P 2}$, who proposed an approach to constraint allocation that stresses the importance of considering that DSs on lower hierarchical level in separate branches might be restricted by the same constraint. Most projects only recorded some side-notes about the complexity of the modelling language. P5, however, received direct feedback from practitioners that the EF-M formalism is too confusing and abstract, "very complex and $[\ldots]$ hard to work with". However, the practitioners also stated that, as a general idea, the EF-M approach to product design appeared beneficial.

In the case example of Figure 2, the challenge of unclear modelling rules can be observed in, e.g., the formulation of the top-level FR - while it already breaks the verb-noun rule, yet still remains very abstract due to the nature of solution independent formulation. Also, the challenge of ordering of FR and DS is illustrated here: is "control gun" a top-level function or a sub-function of the DS "casing"? The same goes for the FR "Place gun down when not in use". Another challenge of abstraction lies in implicit functions: is "Protect user from heat" a function on its own, or should it be modelled as a constraint on the DS "Casing"? The EF-M method does not answer these questions, nor provide guidance on what kind of solution to prefer.

\subsubsection{Lack of behaviour modelling (C2)}

The EF-M formalism, as it is defined, cannot describe the performance of the established product design. P3 reflected upon the lack of support gained from a function-means model of a product design for fact-based decisions regarding product performance. Thus, more knowledge regarding the product design needs to be accumulated later in the design process. In P5, the EF-M model was complemented with DSMs and a change propagation method to make up for this deficit. P6 and $\mathbf{P 7}$ both connected the EF-M model to CAD models, $\mathbf{P 7}$ even physical prototypes, to simulate and analyse product behaviour. In P6, a series of subsequent CAE methods, structural and thermodynamic finite element analysis was applied. P8 applied Pugh's complexity factor to assess manufacturing consequences.

\subsubsection{Lacking coupling to manufacturing process representation (C3)}

EF-M models only capture an isolated model in one life-cycle phase of a product, most commonly the use phase. This proved to be a challenge in $\mathbf{P 3}$ and $\mathbf{P 4}$, which was addressed by complementing the EF-M models with "operations platforms" models where the product and production system architectures were joined in modelled interactions and hence, facilitate concurrent engineering.

Further support to EF-M models was illustrated in P6, where the EF-M model was expanded by a producibility model (Madrid et al., 2016). This was done to enable integrated modelling of product and production system joining in the production processes. 


\subsubsection{Need for geometrical embodiment (C4)}

The need for a connection of the method to geometry models has been the most wide-spread challenge of the application of EF-M, in the way that it occurs in all projects except for P5.

$\mathbf{P 1}$ described the product in terms of variant parameters, and a similar approach was used in $\mathbf{P 2}$, where geometrical properties were described in terms of design parameters in a separate excel-sheet. Similarly, $\mathbf{P 8}$ provided geometrical descriptions of the concepts by enhancing the DSs in the EF-M model with design parameters. P3 reflected on the challenge of lack of physical embodiment not providing fact-based grounds for further work with product concepts. P4 describes the need of component trees of the product and production system, similar to BOM and BOE, respectively, to accomplish modelling of production processes. P7 noticed that physical embodiment descriptions and geometrical product definition as crucial requirements for additive manufacturing (AM) qualification and simulations and thus, supported the lack of these with CAD models and simulations. Similarly, in P6, CAD models were used as a basis for product behaviour simulation and analysis.

\section{Discussion}

From publications about research projects using EF-M analysed in this report, four main uses for EF-M modelling could be identified: Mass customization, Concurrent engineering, Set-based design and Design space exploration The application of these has been evenly spread over the different research projects, supporting the claim for versatility that has been made for EF-M (Johannesson and Claesson, 2005). One of the mainly used benefits is that of EF-M as a knowledge capturing tool, B4, (in P1-P2, P4P5, P7-P9) which correlates with the premise of Malmqvist (1997) of FM as a method of DR and product knowledge representation. This relates to a common FM benefit, shared with other FM approaches, where it is not only used to understand the established design, but also to identify how design knowledge can be reused, how variability in design can be achieved and pinpoint where redesign should take place.

The way of representing the design space, through discrete limitations (B7) as well as the openness to model new solutions (B1), used in most projects (P3, P5, P7-P9), is a more specific property of the EF-M method. Most other methods, such as the integrated FM framework (Eisenbart et al., 2015), focus on the representation and analysis of only a single concept. This ability also is the basis for the use of EF-M in set-based engineering as well as design space exploration, which has mainly been observed in the later uses of EF-M (P3, P7-P8). In some projects (P2-P3, P8), the challenge of the high level of abstraction (C1) of FM as a hinder for application was noted and resonates with observations from other FM studies (Eckert et al., 2012).

The examined projects have been limited to mechanical design. Application reaching beyond design are present, for example P3, P4 and P7 have studied integrated product and production design but have they only touched upon the field of production process modelling. This observation is insofar interesting as EF-M is claimed by (Claesson, 2006) to be usable to model inter-disciplinary systems, be they physical or none, e.g. parts, software, electronics. Possible explanations for the focus of applying EF-M mainly on mechanical design cases can be the focus of the research groups, but also that in other engineering domains other systems engineering tools and methods are already established, such as UML, SysML or Simulink. The field of mechanical engineering, however, is still lacking an established method for rationale and systems modelling (Tomiyama et al., 2013).

The two main challenges observed were the lack of behaviour modelling (C2) in EF-M and the lack of a formalism for embodiment (C4) of the individual concepts. Where EF-M expresses explicitly the expected behaviour of a product, i.e. the function in the FR as verb-noun pairs (similar to the functional basis (Hirtz et al., 2002) or short statements, no feature of the method expresses the actually shown behaviour of the concept or individual solutions. Looking at the function-behaviour-structure (FBS) model (Gero and Kannengiesser, 2004), to be able to perform an evaluation of the design a modelling of the behaviour is necessary, since it is the comparison of expected behaviour (FR in EFM) to actual behaviour - derived from a structure. However, systemic analysis is claimed as a benefit of EF-M (B3). Furthermore, $\mathbf{P 8}$ found that "available product knowledge [can be] stored in the EF-M model", including behaviour representing product data. While this might pose a workaround to capture certain behaviour, the lack of a formal and robust modelling mechanism for this can be seen as a clear 
limitation of EF-M. Further, (Michaelis et al., 2015) pointed out that EF-M models "are not aimed at describing transformations", a feature found in other FM approaches such as the black-box model in (Pahl et al., 2003). This can explain why many of the studied projects (P5-P9) made use of other engineering models and methods, such as CAE, for this purpose.

While mentioned as necessary in FBS, the products structure or geometry, is also not available in EF$\mathbf{M}$. This shows directly in $\mathbf{C 4}$, the lack of geometrical embodiment. The lack of a mechanism to couple both the EF-M model to a geometry model, as well as the reverse connection of product behaviour data from the geometry and CAE tools back to the function model is a major limitation of this FM method. common use of CAD as a combined method with EF-M is a clear indicator for that.

In this publication several challenges of the EF-M modelling method have been pointed out. However, for only very few of them solutions can be provided at this point. Where Tomiyama et al. (2013) pointed out new directions for their identified challenges, such as use of FM for validation or redundancy design, the further development of the actual modelling approach is seen as a more important contribution of further work. If the weaknesses in applying FM in general, or EF-M in this specific case, can be addressed in further versions of the methods, such as tighter coupling of FM to CAD or a less abstract modelling approach, FM may become reliable tool for product development.

\section{Conclusions and future work}

This publication is a first follow-up study of the EF-M method and various applications in industrial contexts to identify the purpose of using said method, as well as benefits and challenges of the method. The usability and applicability of EF-M modelling has been studied for nine different projects from the years in between 2006 and 2019, delimited to applied cases of EF-M on industrial products. All these cases were concerned with the design of mechanical product components, furthermore in a quite limited range of industries. The exact reason for this could not be denoted, however, it points towards a need for further studies of the use of EF-M in fields such as software or electric engineering.

EF-M proves to support mass customization, concurrent engineering, set-based design as well as design space exploration through various general function modelling benefits as well as some unique ones such as the combined support of bottom-up and top-down modelling or the continuously open design space. However, the specific challenges identified in this research may be pointed out as reasons as to why this FM approach has not been established as an industrial application yet. Almost all observed projects noted challenges in the generation and/or maintenance of the actual models commonly to be traced to a too abstract modelling approach. Possible remedies for this limitation are a further development into an advanced computer supported modelling tool and user interface, or further education of practitioners in the use of FM.

Several projects made use of other product representations, most often in the form of CAD models. Thus, although EF-M does provide architectural as well as systemic product knowledge and analysis possibilities, it is not a sufficient stand-alone product model. However, most publications report challenges in coupling other product models or representations to the EF-M model. While this may be due to challenges in the implementation into software tools, this is a target for further research, especially in the connection of EF-M to CAD models.

Finally, execution of the EF-M models has only been used for the purpose of evaluative support, i.e. the resulting performance of an established product design has been assessed. No approaches to usage of the models as generative support has been demonstrated, i.e. generating design information of the product when the desired performance of the product is defined. How the EF-M model can be used in the generative mode can be an interesting field to be further explored.

\section{References}

Borgue, O. et al. (2018), "Function modelling and constraints replacement for additive manufacturing in satellite component design", Proceedings of NordDesign 2018, No. August.

Eckert, C.M. et al. (2012), "Variations in functional decomposition for an existing product: Experimental results", Artificial Intelligence for Engineering Design, Analysis and Manufacturing (AIEDAM), Cambridge University Press, Vol. 26 No. 02, pp. 107-128. 
Eisenbart, B., Gericke, K. and Blessing, L. (2015), "DSM for modeling and analyzing functionality: Views of practitioners", Modeling and Managing Complex Systems - Proceedings of the 17th International DSM Conference, No. November. available at: https://doi.org/10.3139/9783446447264.016

Gedell, S. and Johannesson, H. (2012), "Design rationale and system description aspects in product platform design: Focusing reuse in the design lifecycle phase", Concurrent Engineering Research and Applications, Vol. 21, pp. 39-53.

Gero, J.S. and Kannengiesser, U. (2004), "The situated function-behaviour-structure framework", Design Studies, Vol. 25 No. 4, pp. 373-391.

Hirtz, J. et al. (2002), "A functional basis for engineering design: Reconciling and evolving previous efforts", Research in Engineering Design, Vol. 13 No. 2, pp. 65-82.

Hubka, V. and Eder, W.E. (1988), Theory of Technical Systems, Springer-Verlag, Springer Berlin Heidelberg, Berlin, Heidelberg. available at: https://doi.org/10.1007/978-3-642-52121-8

Johannesson, H. and Claesson, A. (2005), "Systematic product platform design: A combined function-means and parametric modeling approach", Journal of Engineering Design, Vol. 16 No. 1, pp. 25-43.

Kang, E., Jackson, E.K. and Schulte, W. (2011), “An Approach for Effective Design Space Exploration”, Foundations of Computer Software. Modeling, Development, and Verification of Adaptive Systems: 16th Monterey Workshop 2010, Redmond, WA, USA

Landahl, J. et al. (2017), "Mediating Constraints Across Design and Manufacturing Using Platform- Based Manufacturing Operations", 21 st International Conference on Engineering Design, ICED 2017.

Levandowski, C.E., Michaelis, M.T. and Johannesson, H. (2014), "Set-based development using an integrated product and manufacturing system platform”, Concurrent Engineering, Vol. 22 No. 3, pp. 234-252.

Malmqvist, J. (1997), "Improved function-means trees by inclusion of design history information", Journal of Engineering Design, Vol. 8 No. 2, pp. 107-117.

Michaelis, M.T., Johannesson, H. and Elmaraghy, H.A. (2015), "Function and process modeling for integrated product and manufacturing system platforms", Journal of Manufacturing Systems, The Society of Manufacturing Engineers, Vol. 36, pp. 203-215.

Müller, J.R., Panarotto, M. and Isaksson, O. (2019), "Connecting functional and geometrical representations to support the evaluation of design alternatives for aerospace components", ICED19: 22nd International Conference on Engineering Design.

Pahl, G. et al. (2003), Konstruktionslehre: Grundlagen Erfolgreicher Produktentwicklung. Methoden Und Anwendung, Chemistry, Springer-Verlag. available at https://doi.org/10.1007/978-1-84628-319-2

Raja, V. and Isaksson, O. (2015), "Generic Functional Decomposition of an Integrated Jet Engine Mechanical Sub System Using a Configurable Component Approach”, In Transdisciplinary Lifecycle Analysis of Systems Proceedings of the 22nd ISPE Inc. International Conference on Concurrent Engineering, July 2023, 2015, pp. 337-346.

Raudberget, D. et al. (2015), "Modelling and assessing platform architectures in pre-embodiment phases through set-based evaluation and change propagation”, Journal of Aerospace Operations, Vol. 3 No. 3, pp. $203-221$.

Schachinger, P. and Johannesson, H. (2000), "Computer modelling of design specifications", Journal of Engineering Design, Taylor \& Francis, Vol. 11 No. 4, pp. 317-329.

Siiskonen, M., Folestad, S. and Malmqvist, J. (2018), “Applying function-means tree modelling to personalized medicines", Proceedings of NordDesign: Design in the Era of Digitalization, NordDesign 2018.

Sobek, D.K., Ward, A.C. and Liker, J.K. (1999), “Toyota's principles of set-based concurrent engineering”, MIT Sloan Management Review, Vol. 40 No. 2, pp. 67-83.

Suh, N.P. (1990), The Principles of Design, Vol. 990, Oxford University Press New York. available at: http://scholar.google.com/scholar?hl=en\&btnG=Search\&q=intitle:The+Principles+of+Design\#0

Tomiyama, T. et al. (2013), "Making function modeling practically usable", Artificial Intelligence for Engineering Design, Analysis and Manufacturing (AIEDAM), Vol. 27 No. 3, pp. 301-309. 